\title{
Harmonising data on the correlates of physical activity and sedentary behaviour in young people: Methods and lessons learnt from the international Children's Accelerometry database (ICAD)
}

Andrew J. Atkin ${ }^{1,2^{*}}$, Stuart J. H. Biddle ${ }^{3}$, Stephanie T. Broyles ${ }^{4}$, Mai Chinapaw ${ }^{5}$, Ulf Ekelund ${ }^{6}$, Dale W. Esliger ${ }^{7}$, Bjorge H. Hansen ${ }^{6}$, Susi Kriemler ${ }^{8}$, Jardena J. Puder ${ }^{9}$, Lauren B. Sherar ${ }^{7}$, Esther M. F. van Sluijs ${ }^{2}$ and On behalf of the International Children's Accelerometry Database (ICAD) Collaborators

\begin{abstract}
Background: Large, heterogeneous datasets are required to enhance understanding of the multi-level influences on children's physical activity and sedentary behaviour. One route to achieving this is through the pooling and co-analysis of data from multiple studies. Where this approach is used, transparency of the methodology for data collation and harmonisation is essential to enable appropriate analysis and interpretation of the derived data. In this paper, we describe the acquisition, management and harmonisation of non-accelerometer data in a project to expand the International Children's Accelerometry Database (ICAD).
\end{abstract}

Method: Following a consultation process, ICAD partners were requested to share accelerometer data and information on selected behavioural, social, environmental and health-related constructs. All data were collated into a single repository for cataloguing and harmonisation. Harmonised variables were derived iteratively, with input from the ICAD investigators and a panel of invited experts. Extensive documentation, describing the source data and harmonisation procedure, was prepared and made available through the ICAD website.

Results: Work to expand ICAD has increased the number of studies with longitudinal accelerometer data, and expanded the breadth of behavioural, social and environmental characteristics that can be used as exposure variables. A set of core harmonised variables, including parent education, ethnicity, school travel mode/duration and car ownership, were derived for use by the research community. Guidance documents and facilities to enable the creation of new harmonised variables were also devised and made available to ICAD users. An expanded ICAD database was made available in May 2017.

Conclusion: The project to expand ICAD further demonstrates the feasibility of pooling data on physical activity, sedentary behaviour and potential determinants from multiple studies. Key to this process is the rigorous conduct and reporting of retrospective data harmonisation, which is essential to the appropriate analysis and interpretation of derived data. These documents, made available through the ICAD website, may also serve as a guide to others undertaking similar projects.

Keywords: Physical activity, Sedentary behaviour, Children, Adolescents, Retrospective harmonisation, Data pooling, ICAD

\footnotetext{
* Correspondence: A.Atkin@uea.ac.uk

${ }^{1}$ School of Health Sciences, Faculty of Medicine and Health Sciences, University of East Anglia, Norwich Research Park, Norwich NR4 7TJ, UK ${ }^{2}$ MRC Epidemiology Unit and UKCRC Centre for Diet and Activity Research (CEDAR), University of Cambridge School of Clinical Medicine, Institute of Metabolic Science, Cambridge Biomedical Campus, Cambridge, UK Full list of author information is available at the end of the article
} 


\section{Background}

Much has been written of the need for very large-scale studies in contemporary epidemiology and public health. [1-4] Often the discussion is framed in the context of genomic research and the exploration of geneenvironment interactions, but many branches of science, including behavioural epidemiology, will benefit from having data on very large numbers of participants. Larger samples typically increase exposure heterogeneity and enhance our ability to explore complex interactions (effect modification) amongst (multi-level) exposures. These qualities are pertinent to the study of physical activity and sedentary behaviour in young people, considered as either determinants of health (exposure) or as targets for behaviour change interventions (outcome). Relative to the adult population, heterogeneity in anthropometric and cardiometabolic health markers is reduced in young people, thus large samples are required to identify the small, but potentially important, associations with components of physical activity. [5, 6] Moreover, current understanding of the determinants of physical activity and sedentary behaviour is limited by a reliance on single-country, relatively small studies that lack exposure heterogeneity and the statistical power required to explore interactions amongst factors from different levels of the ecological model. [7, 8]

One response to the need for larger-scale epidemiological studies has been to establish new cohorts, such as UK Biobank $[9,10]$ or the Kadoorie Biobank $[11,12]$, which have collected detailed genetic and phenotypic information on many thousands of participants and followed them over time. As these resources mature they will provide invaluable scientific insight into a range of complex outcomes, but such studies require significant financial investment, are logistically complex and limited in scope by the need to manage participant burden. Moreover, most of these new cohorts focus exclusively on the adult population, with efforts to conduct studies of a similar scale in young people, through the formation of new birth cohorts for example, proving to be extremely challenging. [13, 14] An alternative approach has been to establish multiple smaller, geographically diverse cohorts in parallel, with each study site using a common methodology, either in its entirety or within specific topic areas. [15-17] This approach serves to limit the burden within each study centre and increases sample heterogeneity but requires consensus amongst collaborators regarding methodology and, again, requires significant financial investment to support data collection. A common limitation of both strategies outlined above is that it can take many years for new cohorts to mature and realise their potential through longitudinal data on both exposures and outcomes. A third option is to combine information from existing studies, sometimes referred to as data pooling. This strategy seeks to maximise heterogeneity and statistical power by combining data from selected studies in such a way that enables simultaneous analysis through one- or two-stage individual participant meta-analysis, details of which can be found elsewhere. [18] It offers a route to meeting the demands of contemporary epidemiology in a shorter timeframe than that needed to establish a new cohort and with reduced financial and logistical demands relative to primary data collection. It also serves to maximise funders' return on their investments through better use of existing data. Data pooling has been widely employed in some fields of research [19] but has been used less frequently in the physical activity domain, particularly with young people. $[20,21]$

A growing body of literature is emerging to address the myriad legal and methodological challenges presented by pooling data across studies, much of which has emanated from the Maelstrom Research collaboration. [19, 22-29] A key challenge lies in the administration and management of data from multiple studies, the complexity of which will vary depending upon whether the data are physically relocated to a central repository, for example, or retained within the host institution. Perhaps the most frequently discussed consideration relevant to data pooling, however, is the derivation of analytical variables that are comparable, or at least more comparable, across contributing studies, a process known as data harmonisation. [19, 21, 27, 30] Central to the harmonisation process is a judgement on whether data from contributing studies are 'inferentially equivalent', meaning that the constructs assessed are sufficiently comparable in their format, function or meaning. This requires consideration not just of whether data can be combined, but whether it should be combined. As noted above, some research teams choose to apply a common methodology across multiple studies or study centres in order to promote comparability of data at the point of collection; this is known as prospective harmonisation. In contrast, retrospective harmonisation refers to a process where efforts to foster comparability are initiated subsequent to data collection, such as through the pooling of data from studies that were hitherto distinct. Judgements relating to the potential for deriving harmonised variables across studies, and what format they might take, impact upon the types of research questions that can be addressed. In addition, these decisions influence how analytical results should be interpreted and applied by researchers, practitioners and policy-makers. Transparency in harmonisation methodology, therefore, is essential to evaluating the validity of results obtained from pooled data analyses and exploring 
their implications for subsequent research or policy. It also facilitates evidence synthesis and replication of analyses, but it is often lacking or insufficient. [19]

The International Children's Accelerometry Database (ICAD) is a large, multi-country data pooling project, concerned with understanding the distribution, determinants and health impacts of objectively measured physical activity in young people ( $\leq 18$ years). [31] ICAD draws together studies conducted in Europe, North and South America and Australia, all of which measured physical activity in young people using the Actigraph (Pensacola, FL) accelerometer. Given its scale and geographic diversity, ICAD is a potentially valuable resource to enhance our understanding of the correlates and determinants of physical activity and sedentary behaviour in young people. This evidence is essential to inform the design of effective behaviour change interventions, but much of the existing literature on this topic is drawn from single-country, cross-sectional studies that relied on self- or proxy reports of the outcome and addressed only a limited set of exposures. [8, 32-34] As detailed below, a key aim of the project to expand ICAD was to add more data on the personal, social and environmental factors that might influence children's physical activity and sedentary behaviour in order the strengthen this evidence base.

The objective of this paper is to describe the data management and harmonisation methodology of ICAD and reflect upon the administrative, logistical and conceptual challenges that characterise work of this nature. More specifically, the paper aims to: 1) provide an overview of the development of ICAD and recent work to expand it; 2) summarise the methods for collating, cataloguing and managing ICAD data; 3) describe procedures for the harmonisation of non-accelerometer data (including examples); 4) discuss future directions for ICAD as a resource, including technical and operational considerations. Our primary focus is on the treatment of the nonaccelerometer data in ICAD, as this has not been described previously in depth. This paper is complimentary to a previous publication describing the design and methods of ICAD, which focussed predominantly on the processing of accelerometer data. [31] It should be noted that all accelerometer data contained within ICAD were reprocessed in 2015/16, with some amendments to the protocol used previously. Updated details on the processing of the accelerometer data is available from the ICAD website (http://www.mrc-epid.cam.ac.uk/research/studies/icad/).

\section{Methods}

ICAD - Background, oversight and access

A collaboration between the Medical Research Council (MRC) Epidemiology Unit and the universities of Bath and Bristol, ICAD was established in 2008 with funding from the UK National Prevention Research Initiative. Building upon the increasing use of accelerometry in physical activity research, ICAD was devised to enhance understanding in 3 key areas: 1) Levels and patterns of physical activity in children from diverse, social and geographic backgrounds; 2) social, cultural, ethnic and geographical determinants of physical activity; 3) doseresponse relationships between components of physical activity and a range of health outcomes. Twenty studies were recruited to join ICAD and deposited data for processing between September 2008 and May 2010. All provided a signed agreement for the inclusion of study data in ICAD. The pooling strategy required all contributors to submit raw (unprocessed) accelerometer data and related non-accelerometer files, along with accompanying questionnaires and protocols, to a single location for processing and merging. As a minimum, partners were required to share their accelerometer data and information on participants' sex, age, height and weight, but were free thereafter to submit as much or as little additional data as they wished. Background information and details on the processing of accelerometer data for this iteration of ICAD has been reported previously. [31]

Currently, day to day management and administration of ICAD is undertaken by the Working Group (AJA, UE, DWE, BHH, LBS, EMFVS), comprising representatives from the University of East Anglia, Loughborough University, the Norwegian School of Sport Sciences and the MRC Epidemiology Unit. Scientific oversight is provided by the Steering Committee, which comprises representatives from all contributing partners and the Working Group. The MRC Epidemiology Unit (University of Cambridge, UK) manages the database and data releases. Through a managed application process, ICAD data are available for use by any bona fide researcher. [35] Further details on the management of ICAD, contributing partners and the application process are available on the ICAD website (http://www.mrc-epid.cam.ac.uk/research/ studies/icad/).

\section{ICAD 2 - Expanding the database}

The first iteration of ICAD contained relatively little information on the personal, social and environmental factors that might interact to influence children's activity. To address this limitation, and strengthen its capacity for the conduct of longitudinal analyses more generally, a project to expand ICAD was initiated in 2014. The expansion focussed on existing ICAD studies, who were invited to submit any additional waves of data that had been collected in their study and data on a broader range of personal, social and environmental characteristics. A shortlist of constructs that were considered potentially valuable additions to 
ICAD was prepared by the Working Group and subsequently circulated to a panel of invited experts (SJHB, STB, MCAP) and the Steering Committee for feedback, amendments and additions. Additional constructs requested for inclusion in ICAD are listed in Table 1. Constructs were defined in broad terms in order to encourage partners to share all potentially relevant variables on each construct.

To facilitate data sharing, summary documents were prepared for each study, detailing what data had been submitted to ICAD at its inception. This document, along with details of the additional variables of interest and instructions for data transfer, was emailed to each study partner and a nominated data manager or co-investigator where appropriate. Partners were also requested to share all relevant supporting material, such as study protocols, standard operating procedures and questionnaires, to inform data cataloguing and harmonisation. Partners were under no obligation to share additional data, and were free to submit as much or as little as they felt appropriate. Data requests were circulated during the second half of 2014 through early 2015 and submission of new data accepted up to the end of 2015. Data cataloguing, processing and harmonisation was undertaken throughout 2016, with a new database released in spring 2017.

\section{Data management}

We requested that accelerometer data were transferred as raw (unprocessed) files, in order that all accelerometer data could be reprocessed under a common protocol. No specification was made for the format of other accompanying data. Following initial checking and storage, two separate teams led on the management and processing of the accelerometer (BHH, LBS, UE, DWE) and nonaccelerometer data (AJA, EMFvS). Accelerometer data were processed using KineSoft version 3.3.80 (KineSoft,

Table 1 Social, behavioural and environmental variables added to ICAD database

\begin{tabular}{|c|c|c|}
\hline Domain & Construct & Description \\
\hline \multirow[t]{5}{*}{ Home and family } & Parental composition & Number of parents/guardians living at home. \\
\hline & Internet access & Availability of internet in the family home. \\
\hline & Number of televisions & Number of televisions in the family home. \\
\hline & Garden & Access to a garden at home. \\
\hline & Home location & City, County/State, Urban/Rural. \\
\hline \multirow[t]{5}{*}{ Physical activity - behaviour and correlates } & $\begin{array}{l}\text { Sport and organised physical } \\
\text { activity }\end{array}$ & Child's participation in sport or other organised physical activities. \\
\hline & Physical activity self-efficacy & Child's self-efficacy for engaging in or increasing physical activity. \\
\hline & Parent support for physical activity & Mother/Father/Guardian support for child's activity. \\
\hline & Peer support for physical activity & Peer support for child's activity. \\
\hline & Parental physical activity & Mother/Father/Guardian physical activity level. \\
\hline \multirow{7}{*}{$\begin{array}{l}\text { Sedentary behaviour - behaviour and } \\
\text { correlates }\end{array}$} & TV in the bedroom & Presence of a television in child's bedroom. \\
\hline & Computer in the bedroom & $\begin{array}{l}\text { Presence of a computer (inc. video games machine) in child's } \\
\text { bedroom. }\end{array}$ \\
\hline & Sedentary behaviour self-efficacy & Child's self-efficacy for reducing sedentary behaviours \\
\hline & $\begin{array}{l}\text { Parent support for sedentary } \\
\text { behaviour }\end{array}$ & Mother/Father/Guardian support for child's sedentary behaviour. \\
\hline & $\begin{array}{l}\text { Peer support for sedentary } \\
\text { behaviour }\end{array}$ & Peer support for child's sedentary behaviour. \\
\hline & Parental television viewing & Mother/Father/Guardian time spent watching television. \\
\hline & Parental computer use & Mother/Father/Guardian time spent using a computer. \\
\hline \multirow[t]{6}{*}{ School factors and other behaviours } & Physical education & Child's engagement in physical education at school. \\
\hline & School start/end time & Start/end time of child's school day. \\
\hline & Sleep duration & Child's sleep duration. \\
\hline & Fruit and vegetables & Child's consumption of fruits and vegetables. \\
\hline & Sugar sweetened beverages & Child's consumption of sugar sweetened beverages. \\
\hline & Breakfast consumption & Whether or not child eats breakfast. \\
\hline
\end{tabular}


Loughborough, United Kingdom). All non-accelerometer data were converted to STATA .dta 'wide' format master files (one row per participant). Where relevant, a prefix was added to variable names to indicate their time of assessment (e.g. W1_X = variable $\mathrm{X}$ at wave 1; W2_X= variable $X$ at wave 2 , etc.).

To inform harmonisation of the non-accelerometer data, a data dictionary was created for each study. Using a pre-prepared Microsoft Excel template, the following information was recorded for each variable: name, short label, detailed description, unit (e.g. $\mathrm{cm}, \mathrm{kg}, \mathrm{mmHg}$ ), and format (e.g. continuous, categorical). The detailed description section included an extended description of the construct being assessed, the method of measurement, and category labels where appropriate. Identification numbers were assigned at the study and variable level to facilitate searching and corrections to be made. Each variable was assigned to a unique 'variable group', which identified the underlying construct to which it related. This was applied uniformly across all studies, enabling us to efficiently identify all variables that related to a particular characteristic. For example, all variables relating to child's mode or duration of travel to school were tagged 'School_travel'. Upon completion, each study template was uploaded to a single Microsoft Access database. The Access query function allowed for efficient and accurate extraction of specific batches of variables, identified using the variable groupings. Harmonised variables were created initially within each study master file and subsequently combined (appended) to create a single data file for data release (harmonisation procedures described below). The data dictionary of harmonised ICAD variables is accessible from the ICAD website (http://www.mrc-epid.cam.ac.uk/research/studies/icad/).

\section{ICAD harmonisation procedures for non-accelerometer data - An overview}

In recognition of the time constraints of the Working Group and the likely personal preferences for harmonisation decisions of prospective users, an a-priori decision was made to create harmonised variables only for a sub-group of available constructs. The selection was based on specific research questions of interest to the Working Group and constructs which were considered to be most valuable to a wide range of prospective users of the updated database (e.g. as confounding variables). The shortlist included socio-demographic characteristics, a small number of candidate determinants of physical activity / sedentary behaviour and a range of anthropometric and metabolic factors. For each construct, information on relevant variables and methodology for all contributing studies was extracted from the data dictionary.
Data dictionary information was reviewed to establish consistencies (and inconsistencies) in the data across studies, and thus determine the potential for deriving harmonised variables. Although different from one construct to the next, key considerations here included: timeframe of assessment (e.g. proximity to accelerometer deployment, number of waves of assessment), data resolution (e.g. categorical vs. continuous), construct equivalence (pertinent for latent or multi-dimensional constructs), data source (indirect vs direct, objective vs subjective measures) and respondent (child- vs. parentcompleted questionnaire). These considerations, amongst others, are discussed in the example below. Where a study collected data on a single construct from multiple sources (e.g. child and parent reported sex), an order of preference was established, along with procedures for dealing with missing or inconsistent data. As a general principle, we sought to create multiple harmonised variables for each construct, balancing the often competing demands of resolution and coverage (number of included studies). This enabled us to create higher resolution variables that made best use of detailed data where it was available and lower resolution variables that allowed for inclusion of the largest number of studies possible. This approach also allowed us to create harmonised variables to reflect the different components of multi-dimensional constructs, such as mode and duration of travel to school.

The complexity of the harmonisation process varied greatly dependent upon the particular characteristics of each construct. For anthropometric, metabolic and some demographic variables (e.g. age, sex), where there was general consistency in definition and assessment, harmonisation was conducted solely by the Working Group. For constructs that were deemed to be more conceptually or methodologically complex (e.g. ethnicity, car ownership, school travel, parent education) harmonised variables were created following an iterative process, with contributions from the Working Group, self-selected members of the Steering Committee (SK, JJP), and our panel of invited experts. The iterative process included four stages. First, one researcher proposed and derived an initial set of harmonised variables for each construct. Detailed documentation summarised the content and format of study-level data, reasons for exclusion of particular studies (or waves within studies) and any processing or recoding required to create the harmonised variables. Following circulation, all feedback was reviewed and amendments made to the format or procedure for creating harmonised variables as appropriate. Relevant documentation was updated and circulated to all parties for final review after which further amendments were made where necessary. 
Detailed documentation was created to describe the data harmonisation process. This included information on the characteristics of the data provided by each study, a description of the harmonised variables created, lists of included/excluded studies/waves (along with relevant justification) and information about how multiple data sources and missing data were dealt with. Study specific notes were also produced, allowing for a more detailed explanation of unique design or methodology issues and how they were addressed. Lastly, tables were prepared to detail any study/wave-specific processing or recoding undertaken. Harmonised variables were created using algorithmic transformation or simple calibration methods. [19]. All harmonisation documentation is available on the ICAD website (http://www.mrc-epid.cam.ac.uk/research/studies/icad/data-harmonisation).

\section{Results}

\section{Data harmonisation example - school travel mode and} duration

The journey to school is a potentially important opportunity for children to accumulate physical activity. [36] Key research questions related to school travel include: "Do children who use active modes of travel to school accumulate more physical activity?" and "Is a change in travel mode associated with changes in physical activity?". Information on school travel was requested when ICAD was first established but only a small number of studies $(n=8)$ provided this data. Additional data on school travel were requested, and received, as part of the expansion project. In this section, we outline the process and key considerations that informed the creation of three harmonised variables relating to school travel.

Fourteen studies $(60 \%)$ provided data on one or more dimension of school travel (e.g. travel mode, duration, frequency). Seven studies provided data for two or more time points, and data were available for 25 study-waves in total. Information was collected by child-report in seven studies, by parent-report in four studies and three studies collected information by both child- and parentreport, either changing between waves or simultaneously from both within a single wave. In the latter case, parent-reported data were used preferentially as this was considered more likely to be reliable across all age ranges. Data referred to travel mode, frequency, duration and either the journey to or from school (or both), but few studies had information on all dimensions. Where information was available on both the journey to and from school, data on travel to school were used preferentially as this was reported most commonly across contributing studies.

Initial review highlighted the potential to create three harmonised variables; two regarding mode of travel and one describing duration of the journey (Table 2). Data from 11 studies (21 waves) were deemed suitable for inclusion in the categorical variable ICAD_SchoolTravel1. Four study-waves were excluded from this variable because the questionnaire items used referred only to walking or cycling to school, omitting other modes of travel such as car or bus. For these studies, we inferred that a response of no walking or cycling to school indicated that they used a non-active travel mode. Accordingly, all study-waves $(n=25)$ were included in the binary harmonised variable (ICAD_SchoolTravel2) which included only active / non-active travel mode categories. Eight studies provided information on duration of the journey to school, hence fewer data (8 studies, 13 waves) are included in the final harmonised variable (ICAD_SchoolTravel3).

An overview of the source data and process for creating ICAD_SchoolTravel2 and ICAD_SchoolTravel3 is provided in Tables 3, 4, and 5 using illustrative data from the SPEEDY, KISS and Ballabeina studies. [37-39] The harmonised variables were created by collapsing categories in the source data or applying the appropriate thresholds to create categories from a continuous variable. For the SPEEDY study (waves 1 and 3), the questionnaire addressed school journey duration by walking and cycling separately but requested a combined estimate of journey duration if the participant travelled by bus or car. Therefore, responses for ICAD_SchoolTravel3 are provided only for those who indicated that they walked or cycled to school. In Ballabeina, information on the duration of the school journey was

Table 2 Overview of school travel harmonised variables

\begin{tabular}{|c|c|c|c|c|c|}
\hline \multirow{3}{*}{$\begin{array}{l}\text { Name } \\
\text { Description }\end{array}$} & \multirow[t]{3}{*}{ Response categories } & \multicolumn{4}{|c|}{ Summary statistics } \\
\hline & & \multirow{2}{*}{$\begin{array}{l}\text { Studies } \\
\text { (n) }\end{array}$} & \multicolumn{3}{|c|}{ Waves ( $\mathrm{n}$ studies) } \\
\hline & & & 1 & 2 & 3 \\
\hline $\begin{array}{l}\text { ICAD_SchoolTravel1. } \\
\text { Mode of travel to school. }\end{array}$ & Walk, Cycle, Public transport, Car, Other, Missing & 11 & 4 & 4 & 3 \\
\hline $\begin{array}{l}\text { ICAD_SchoolTravel2. } \\
\text { Mode of travel to school }\end{array}$ & Active mode of travel, Other mode of travel, Missing & 14 & 7 & 3 & 4 \\
\hline $\begin{array}{l}\text { ICAD_SchoolTravel3. } \\
\text { Duration of journey to school. }\end{array}$ & $\begin{array}{l}\text { Less than or equal to } 5 \mathrm{~min}, 6-15 \mathrm{~min} \text {, More than } \\
15 \mathrm{~min} \text {, Missing }\end{array}$ & 8 & 4 & 3 & 1 \\
\hline
\end{tabular}


Table 3 Assessment of school travel mode and duration: Examples from three studies

\begin{tabular}{|c|c|c|c|}
\hline & SPEEDY & KISS & Ballabeina \\
\hline Respondent & Child-reported. & Parent-reported. Translated from German. & $\begin{array}{l}\text { Parent-reported. Translated } \\
\text { from French/German. }\end{array}$ \\
\hline $\begin{array}{l}\text { Item: } \\
\text { Mode }\end{array}$ & $\begin{array}{l}\text { How do you usually travel to school? } \\
\text { Response options: Car; Bus/Train; Bicycle; On foot. }\end{array}$ & $\begin{array}{l}\text { How does your child usually travel to school and } \\
\text { how long does it take when following the most } \\
\text { direct route (please name only the most common } \\
\text { mode of transport). } \\
\text { Response options: Walk; Bicycle/Scooter; Car; } \\
\text { Bus/Train/Tram. }\end{array}$ & $\begin{array}{l}\text { How does your child make } \\
\text { it to school? } \\
\text { Response options: Walk; } \\
\text { Bicycle/Scooter; Bus/Tram; } \\
\text { Car; Other. }\end{array}$ \\
\hline $\begin{array}{l}\text { Item: } \\
\text { Duration }\end{array}$ & $\begin{array}{l}\text { For the previous } 7 \text { days: Each time you did this } \\
\text { (prompts: walk to school; cycle to school; travel } \\
\text { to school by car / bus), how long did you normally } \\
\text { do it for? } \\
\text { Estimated as free text in minutes. }\end{array}$ & $\begin{array}{l}\text { See above. } \\
\text { Estimated as free text in minutes. }\end{array}$ & $\begin{array}{l}\text { What is the duration of the } \\
\text { trip (one way) to get to } \\
\text { school? } \\
\text { Response options: }<10 \text { min; } \\
10-20 \text { min; }>20 \text { min. }\end{array}$ \\
\hline $\begin{array}{l}\text { Item: } \\
\text { Frequency }\end{array}$ & $\begin{array}{l}\text { For the previous } 7 \text { days: How many times did you } \\
\text { do this activity (prompts: walk to school; cycle to } \\
\text { school; travel to school by car / bus). } \\
\text { Response options: Never; Once; } 2 \text { to } 3 \text { times; } 4 \text { or } \\
\text { more times. }\end{array}$ & N/A & N/A \\
\hline
\end{tabular}

For brevity, details are provided for data collected at study wave 1 only

collected in two waves of assessment; however, the response categories used were not compatible with those selected for the harmonised variable. Therefore no data from this study were included in ICAD_SchoolTravel3. Complications of a comparable nature were encountered in other studies, including the use of questionnaires that allowed for the selection of multiple modes and frequencies of travel to school and the use of different questionnaires within sample subgroups. All such issues are discussed in the 'study-specific notes' section of accompanying documentation, available from the data harmonisation section of the ICAD website.

\section{Discussion}

This paper provides background information and outlines the rationale and methodology for the expansion of a large, multi-study repository of accelerometer data in young people. ICAD remains unique within the field and the expansion work outlined herein serves to broaden its scope and facilitate the conduct of longitudinal analyses. For the benefit of ICAD users and those undertaking similar work, we sought to provide methodological transparency on our approach to data collation and harmonisation. Below we discuss our methods in the context of other data-pooling projects in the field of epidemiology more broadly, reflect upon some of the

Table 4 Overview of source data from three studies and harmonisation process for derivation of ICAD_SchoolTravel2

\begin{tabular}{|c|c|c|c|c|c|}
\hline \multicolumn{3}{|c|}{ Source data } & \multicolumn{3}{|c|}{ Harmonisation } \\
\hline $\begin{array}{l}\text { Study } \\
\text { Wave }\end{array}$ & Variable(s): name(s), description & Summary & Category & Processing & Summary \\
\hline \multirow{3}{*}{$\begin{array}{l}\text { SPEEDY } \\
\text { Wave: } 1\end{array}$} & \multirow{3}{*}{$\begin{array}{l}\text { Variable name: } \\
\text { W1_school_travel } \\
\text { Mode of travel to school }\end{array}$} & \multirow{3}{*}{$\begin{array}{l}\text { Car, } n=923 \\
\text { Bus/train, } n=127 \\
\text { Bicycle, } n=189 \\
\text { On foot, } n=814 \\
\text { Missing, } n=11\end{array}$} & Active mode & If [W1_school_travel] = Bicycle OR On foot & $n=1003$ \\
\hline & & & Other mode & If [W1_school_travel] = Car OR Bus/train & $n=1050$ \\
\hline & & & Missing & If [W1_school_travel] = Missing & $\mathrm{n}=11$ \\
\hline \multirow[t]{3}{*}{$\begin{array}{l}\text { KISS } \\
\text { Wave: } 1\end{array}$} & \multirow{3}{*}{$\begin{array}{l}\text { Variable name: } \\
\text { a_schulweg_hin_sommer } \\
\text { Mode of travel to school during } \\
\text { summer }\end{array}$} & \multirow{3}{*}{$\begin{array}{l}\text { Walk, } n=392 \\
\text { Cycle/scooter, } \\
n=51 \\
\text { Car, } n=7 \\
\text { Bus/train/tram, } \\
n=3 \\
\text { Missing, } n=87\end{array}$} & Active mode & $\begin{array}{l}\text { If [a_schulweg_hin_sommer] = Walk OR Cycle/ } \\
\text { scooter }\end{array}$ & $n=443$ \\
\hline & & & Other mode & $\begin{array}{l}\text { If [a_schulweg_hin_sommer] = Car OR Bus/train/ } \\
\text { tram }\end{array}$ & $n=10$ \\
\hline & & & Missing & If [a_schulweg_hin_sommer] = Missing & $n=87$ \\
\hline \multirow{3}{*}{$\begin{array}{l}\text { Ballabeina } \\
\text { Wave: } 1\end{array}$} & \multirow{3}{*}{$\begin{array}{l}\text { Variable name: } \\
\text { W1_a_schulweg } \\
\text { Mode of travel to school }\end{array}$} & \multirow{3}{*}{$\begin{array}{l}\text { Walk, } n=546 \\
\text { Cycle/scooter, } n=1 \\
\text { Bus/tram, } n=4 \\
\text { Car, } n=32 \\
\text { Other, } n=24 \\
\text { Missing, } n=62\end{array}$} & Active mode & If [W1_a_schulweg] = Walk OR Cycle/scooter & $n=547$ \\
\hline & & & Other mode & If [W1_a_schulweg] = Bus OR Car OR Other & $n=60$ \\
\hline & & & Missing & If [W1_a_schulweg] = Missing & $n=62$ \\
\hline
\end{tabular}


Table 5 Overview of source data from three studies and harmonisation process for derivation of ICAD_SchoolTravel3

\begin{tabular}{|c|c|c|c|c|c|}
\hline \multicolumn{3}{|c|}{ Source data } & \multicolumn{3}{|c|}{ Harmonisation } \\
\hline $\begin{array}{l}\text { Study } \\
\text { Wave }\end{array}$ & Variable(s): name(s), description & Summary & Category & Processing & $\overline{\text { Summary }}$ \\
\hline \multirow[t]{4}{*}{$\begin{array}{l}\text { SPEEDY* } \\
\text { Wave: } 1\end{array}$} & \multirow{4}{*}{$\begin{array}{l}\text { Variable names: } \\
\text { W1_a2acthrs_clean } \\
\text { W1_a2actmins_clean } \\
\text { W1_a3acthrs_clean } \\
\text { W1_a3actmins_clean } \\
\text { Duration of journey } \\
\text { when walking or } \\
\text { cycling to school }\end{array}$} & \multirow{4}{*}{$\begin{array}{l}\text { Continuous variables. } \\
\text { Duration when walking in } \\
\text { minutes per day } \\
\text { Mean: } 12.7 \\
\text { Median: } 10 \\
\text { 25th percentile: } 5 \\
\text { 75th percentile: } 15 \\
\text { Range: } 0,60 \\
\text { Duration when cycling in } \\
\text { minutes per day } \\
\text { Mean: } 11.2 \\
\text { Median: } 10 \\
\text { 25th percentile: } 5 \\
\text { 75th percentile: } 15 \\
\text { Range: } 0,60\end{array}$} & $\begin{array}{l}\text { Less than } \\
5 \text { min }\end{array}$ & If duration of walking or cycling $<=5$ & $n=356$ \\
\hline & & & $6-15 \min$ & $\begin{array}{l}\text { If duration of walking or cycling =6-15 } \\
\text { (inclusive) }\end{array}$ & $n=432$ \\
\hline & & & $\begin{array}{l}\text { More than } \\
15 \text { min }\end{array}$ & If duration of walking or cycling $>15$ & $n=193$ \\
\hline & & & Missing & & $n=1083$ \\
\hline \multirow[t]{4}{*}{$\begin{array}{l}\text { KISS } \\
\text { Wave: } 1\end{array}$} & \multirow{4}{*}{$\begin{array}{l}\text { Variable name: } \\
\text { a_schulweg_hin_sommer_time } \\
\text { Duration of journey to school }\end{array}$} & \multirow{4}{*}{$\begin{array}{l}\text { Continuous variable. } \\
\text { Duration in minutes } \\
\text { per day: } \\
\text { Mean: } 9.9 \\
\text { Median: } 10 \\
\text { 25th percentile: } 5 \\
\text { 75th percentile: } 15 \\
\text { Range: } 1,30 \\
\text { Missing, } n=88\end{array}$} & $\begin{array}{l}\text { Less than } \\
5 \mathrm{~min}\end{array}$ & If [a_schulweg_hin_sommer_time] $<=5$ & $n=153$ \\
\hline & & & $6-15 \min$ & $\begin{array}{l}\text { If [a_schulweg_hin_sommer_time] =6-15 } \\
\text { (inclusive) }\end{array}$ & $n=249$ \\
\hline & & & $\begin{array}{l}\text { More than } \\
15 \text { min }\end{array}$ & If [a_schulweg_hin_sommer_time] >15 & $n=50$ \\
\hline & & & Missing & $\begin{array}{l}\text { If [a_schulweg_hin_sommer_time] } \\
=\text { Missing }\end{array}$ & $n=88$ \\
\hline $\begin{array}{l}\text { Ballabeina } \\
\text { Wave: } 1\end{array}$ & $\begin{array}{l}\text { Variable name: } \\
\text { W1_a_langeweg } \\
\text { Duration of journey to school }\end{array}$ & $\begin{array}{l}\text { Categorical variable: } \\
<10 \min , n=514 \\
10-20 \min , n=82 \\
>20 \min , n=10 \\
\text { Missing, } n=63\end{array}$ & \multicolumn{3}{|c|}{$\begin{array}{l}\text { Response categories for this study captured different duration } \\
\text { boundaries to those of the harmonised variable and could } \\
\text { not be suitably collapsed or otherwise matched. Therefore, } \\
\text { this study was not included in the harmonised variable. }\end{array}$} \\
\hline
\end{tabular}

For brevity, processing is summarised for data collected at study wave 1 only. Similar procedures were used for subsequent waves. *The SPEEDY questionnaire did not allow for separate estimation of journey duration amongst those who travelled by bus/train or car to school. Therefore, only participants who indicated walk or cycle as their mode of travel were included in his variable

challenges encountered and consider future directions for ICAD.

Logistical and methodological challenges of data pooling ICAD is a large multi-partner, multi-country collaboration and is, therefore, subject to the same challenges of any such project, be it data pooling, primary data collection or otherwise. These include managing conflicting priorities amongst partners, maintaining effective and timely lines of communication, and managing large volumes of data. The ICAD approach to data pooling entailed submission of data to a single institution, with all subsequent data management, cataloguing and harmonisation undertaken by the Working Group. This approach was adopted to minimise the burden on individual partners and thus maximise their engagement with the project, but this placed significant burden on the Working Group. Some of the studies included in ICAD are historic or little used outside of the ICAD context, therefore there were sometimes challenges in obtaining information on the collection or derivation of particular variables. This limited the completeness of information that could be provided in the data dictionary for these studies.

As a data pooling methodology, collation into a centralised repository, as implemented in ICAD, is advantageous as it allows data to be analysed at the individual-level. [18] However, ethical issues and concerns over confidentiality and protection of intellectual property limit the application of this method and may dissuade, or even preclude, participation of some studies in projects of this kind. [22, 25, 26] Alternatives to centralised pooling, which allow study data to be retained within the host institution, may be more consistent with ethical requirements for some studies and help to allay fears over data security and confidentiality. In such cases, study-specific analyses may be undertaken by each study team, following an analysis plan prepared by the lead investigators. Study-level estimates are then submitted to the lead investigator where they are combined by meta-analysis. This approach, commonly used in genetic epidemiology, is potentially burdensome for each study investigator, as they are responsible for data harmonisation and analysis. Another option is to 
use a federated infrastructure, which allows for analysis at the individual level, undertaken by the lead investigator, whilst data are retained on local servers. $[22,23,25,26]$ This is achieved by the parallel analysis of individual study data, co-ordinated from a central computer over a secure internet connection (HTTPS). This approach represents perhaps the best combination of analytical flexibility and compliance with ethical and confidentiality issues currently available, though it requires a relatively complex technological infrastructure compared to other methods and is still under development. However, given its numerous advantages, elements of the federated approach may be appropriate for inclusion in future iterations of ICAD.

\section{Data harmonisation}

A growing body of literature is emerging that deals with the ethical, methodological and technological issues that arise from data pooling and retrospective data harmonisation. [19, 21, 22, 29] A primary limitation of much previous work of this nature was a lack of methodological clarity, an issue which we have sought to address directly through this paper and related material on the ICAD website. For our initial data release of an expanded ICAD, we focussed on a subset of core variables for harmonisation and sought input from a range of subject experts. This proved extremely valuable with numerous amendments or additions made as a result of their feedback. Nonetheless, we recognise that others may contest the format or content of existing harmonised variables. Accordingly, we are keen to support other researchers in deriving their own harmonised variables and have developed a secure platform through which they can access raw study-level data to facilitate this. This system can also be used to create harmonised variables for the many constructs not currently included in the database, such as dietary behaviours and characteristics of the home and family. We have prepared a guidance document and template form to allow users to record the process of deriving new harmonised variables; this will be published and new variables uploaded to the database for further use.

\section{Future directions}

To this point, work to expand ICAD has focussed upon collating more data from existing partners. As we consider further developments in the years to come, one avenue would be to recruit new partners into the consortium. Indeed our initial plans for expanding ICAD included the recruitment of new studies but as the project progressed it became apparent that this would not be possible within our preferred timeline and staffing capacity and this phase was put on hold. Upon release of the new database, discussions concerning the recruitment of new partners into ICAD will be reinstated. This discussion will include consideration of the scientific value of establishing new partnerships and how new studies would be identified and prioritised for inclusion, taking account of population representation (e.g. particular age groups, representation of low and middle-income countries) amongst other things. In addition, developments in activity assessment (such as wrist-based monitoring and the collection of raw acceleration data) mean there is a need to consider whether and how to incorporate studies that used other devices and/or body placements. This point notwithstanding, there remains a large number of existing studies that used methods compatible with ICAD (e.g. Actigraph, waist-worn monitors) that may be valuable additions to the database. Any future plans to expand ICAD would also require careful reflection on the administrative and technological approach to data collation and harmonisation, acknowledging the need to distribute the burden of work equitably amongst study personnel, ICAD users, the Working Group and support staff. There may be value in exploring other approaches to data storage and the steps that can be taken to facilitate accessible and efficient data harmonisation and analysis by ICAD users. We welcome expressions of interest from principal investigators interested in joining ICAD and insights from a methodological or technological perspective that would feed into our discussions on this topic.

\section{Strengths and limitations}

Through this paper and material posted on the ICAD website, we have described our methods of harmonising data from multiple studies on the correlates of physical activity in young people. In so doing, we sought to address a well-recognised limitation of much previous work of this nature; that is, a lack of transparency in data processing and harmonisation. [19] We undertook extensive data cataloguing at the study-level and of harmonised variables, enabling ICAD users and the wider research community to fully understand the data available for analysis and to enable them to derive new harmonised variables where necessary. The format and content of existing variables was determined iteratively, with input from the ICAD Steering Committee and invited subject experts. The following limitations are acknowledged. Firstly, the burden of data preparation and cataloguing (for both accelerometer and nonaccelerometer data) fell heavily on the ICAD Working Group. Whilst beneficial in terms of consistency and partner engagement, this model would not be sustainable in future developments of the database and alternative approaches, such as requesting that partners undertake some of this preparatory work themselves, will need to be explored. We also acknowledge that despite our rigorous approach to data harmonisation, these decisions are 
subjective and other researchers may disagree with the content of existing variables. In such cases, under secure data conditions, we will enable researchers to access study-level data, allowing them to create new harmonised variables to their preferred specification.

ICAD is currently the largest existing repository of accelerometer data in young people, with data available for approximately 30,000 individuals between the ages of 3 and 18 years. The expanded database includes longitudinal physical activity data from 13 studies, greatly improving its capacity for the conduct of longitudinal analyses relative to its predecessor. Alongside the accelerometer data, information is available for a range of demographic, anthropometric, metabolic, behavioural and environmental characteristics. Limitations of ICAD include the relative under-representation of certain age groups $(<8$ years) and participants from low- and middle-income countries. The majority of partner studies do not comprise nationally representative samples, thus findings of physical activity prevalence for example, should be generalised with caution. Lastly, although every effort was made to obtain information on study protocols and instrumentation, we were unable to capture any verbal instructions or guidance provided to participants by the data collection teams at the point of assessment. Such instructions, however, are likely to have been uniform within each study and of minimal influence of participant responses.

\section{Recommendations}

Herein we provide general recommendations to facilitate the process of pooling and harmonising epidemiological data. These will likely be relevant to a range of research settings, beyond the specific population and topic addressed in this paper.

1. Consider the potential for data sharing at the point of project initiation and, where appropriate, request support from funders to facilitate this.

2. Ensure that participants are informed of, and consent to, the possibility of their data being used beyond the original study.

3. Potential for data sharing and harmonisation may inform instrument selection and application. High resolution data are more amenable to retrospective harmonisation than low resolution data.

4. Establish structured and transparent data management processes. Include data management expertise in the project team and, where possible, retain for the entire duration of the project.

5. Ensure that study administration is detailed and complete. This may include a protocol of recruitment and measurement procedures, and the preparation of 'standard operating procedures'
(SOPs), data dictionaries and syntax libraries of data management and cleaning processes.

6. Data pooling terms and conditions should be outlined in formal data sharing and user agreements, and agreed by all partners.

\section{Conclusion}

The ICAD expansion project demonstrates that largescale pooling of data related to young people's physical activity, and its associated correlates and health outcomes, is feasible. A rigorous and transparent process of retrospective data harmonisation facilitates the conduct of pooled analyses. This work has greatly enhanced capacity for the conduct of longitudinal analyses and exploration of the determinants of physical activity across childhood and adolescence in ICAD. Details of our methodology for data collation and harmonisation are provided to assist those undertaking similar projects, aid the analysis and interpretation of data and facilitate widespread use of this resource.

\section{Acknowledgements}

We would like to thank all participants and funders of the original studies that contributed data to ICAD. The ICAD Collaborators include: Prof LB Andersen, Department of Teacher Education and Sport, Western Norwegian University of Applied Sciences, Sogndal, Norway (Copenhagen School Child Intervention Study (CoSCIS)); Prof S Anderssen, Norwegian School for Sport Science, Oslo, Norway (European Youth Heart Study (EYHS), Norway); Dr. AJ Atkin, School of Health Sciences, University of East Anglia, Norwich, UK; Prof G Cardon, Department of Movement and Sports Sciences, Ghent University, Belgium (Belgium Pre-School Study); Centers for Disease Control and Prevention (CDC), National Center for Health Statistics (NCHS), Hyattsville, MD USA (National Health and Nutrition Examination Survey (NHANES)); Dr. R Davey, Centre for Research and Action in Public Health, University of Canberra, Australia (Children's Health and Activity Monitoring for Schools (CHAMPS)); Prof U Ekelund, Norwegian School of Sport Sciences, Oslo, Norway; Dr. DW Esliger, School of Sports, Exercise and Health Sciences, Loughborough University, UK; Dr. P Hallal, Postgraduate Program in Epidemiology, Federal University of Pelotas, Brazil (1993 Pelotas Birth Cohort); Dr. BH Hansen, Norwegian School of Sport Sciences, Oslo, Norway; Prof KF Janz, Department of Health and Human Physiology, Department of Epidemiology, University of lowa, lowa City, US (lowa Bone Development Study); Prof S Kriemler, Epidemiology, Biostatistics and Prevention Institute, University of Zürich,

Switzerland (Kinder-Sportstudie (KISS)); Dr. N Møller, University of Southern Denmark, Odense, Denmark (European Youth Heart Study (EYHS), Denmark); Ms. L Molloy, School of Social and Community Medicine, University of Bristol, UK (Avon Longitudinal Study of Parents and Children (ALSPAC)); Dr. A Page, Centre for Exercise, Nutrition and Health Sciences, University of Bristol, UK (Personal and Environmental Associations with Children's Health (PEACH)); Prof R Pate, Department of Exercise Science, University of South Carolina, Columbia, US (Physical Activity in Pre-school Children (CHAMPS-US) and Project Trial of Activity for Adolescent Girls (Project TAAG)); Dr. JJ Puder, Service of Endocrinology, Diabetes and Metabolism \& Service of Pediatric Endocrinology, Diabetology and Obesity, Lausanne University Hospital, Lausanne, Switzerland (Ballabeina Study); Prof J Reilly, Physical Activity for Health Group, School of Psychological Sciences and Health, University of Strathclyde, Glasgow, UK (Movement and Activity Glasgow Intervention in Children (MAGIC)); Prof J Salmon, School of Exercise and Nutrition Sciences, Deakin University, Melbourne, Australia (Children Living in Active Neigbourhoods (CLAN)); Prof LB Sardinha, Exercise and Health Laboratory, Faculty of Human Movement, Universidade de Lisboa, Lisbon, Portugal (European Youth Heart Study (EYHS), Portugal); Dr. LB Sherar, School of Sports, Exercise and Health Sciences, Loughborough University, UK; Dr. A Timperio, Centre for Physical Activity and Nutrition Research, Deakin University Melbourne, Australia (Healthy Eating and Play Study (HEAPS)); Dr. EMF van Sluijs, MRC Epidemiology Unit \& Centre for Diet and Activity Research, University of Cambridge, UK (Sport, Physical activity and Eating behaviour: Environmental Determinants in Young people (SPEEDY). 


\section{Funding}

The pooling of the data was funded through a grant from the National Prevention Research Initiative (Grant Number: G0701877) (http:// www.mrc.ac.uk/research/initiatives/national-prevention-research-initiativenpri/). The funding partners relevant to this award are: British Heart Foundation; Cancer Research UK; Department of Health; Diabetes UK; Economic and Social Research Council; Medical Research Council; Research and Development Office for the Northern Ireland Health and Social Services; Chief Scientist Office; Scottish Executive Health Department; The Stroke Association; Welsh Assembly Government and World Cancer Research Fund. This work was additionally supported by the Medical Research Council [MC_UU_12015/3; MC_UU_12015/7], The Research Council of Norway (249,932/F20), Bristol University, Loughborough University and the Norwegian School of Sport Sciences. The work of Andrew J Atkin and Esther M F van Sluiis was supported, wholly or in part, by the Centre for Diet and Activity Research (CEDAR), a UKCRC Public Health Research Centre of Excellence (RES-590-28-0002). Funding from the British Heart Foundation, Department of Health, Economic and Social Research Council, Medical Research Council, and the Wellcome Trust, under the auspices of the UK Clinical Research Collaboration, is gratefully acknowledged. The work of Esther MF van Sluijs was supported by the Medical Research Council (MC_UU_12015/7)

\section{Availability of data and materials}

The data that support the findings of this study are available from MRC Epidemiology Unit, Cambridge but restrictions apply to the availability of these data, which were used under license for the current study, and so are not publicly available. Data are however available from the authors upon reasonable request and with permission of MRC Epidemiology Unit, Cambridge.

\section{Authors' contributions}

AJA, UE, BHH, DWE, LBS, and EMFVS conceived the study and contributed to data acquisition, management and harmonisation. SJHB, STB, MC, SK, and JJP additionally contributed to data harmonisation. AJA drafted the manuscript and all authors provided critical review on manuscript content. All authors approved the final version of the manuscript.

\section{Ethics approval and consent to participate}

All studies pooled within the International Children's Accelerometry Database obtained relevant ethical approval. Participants and/or their legal guardians provided assent/consent as appropriate.

\section{Consent for publication}

Not applicable.

\section{Competing interests}

The authors declare that they have no competing interests.

\section{Publisher's Note}

Springer Nature remains neutral with regard to jurisdictional claims in published maps and institutional affiliations.

\footnotetext{
Author details

${ }^{1}$ School of Health Sciences, Faculty of Medicine and Health Sciences, University of East Anglia, Norwich Research Park, Norwich NR4 7TJ, UK. ${ }^{2}$ MRC Epidemiology Unit and UKCRC Centre for Diet and Activity Research (CEDAR), University of Cambridge School of Clinical Medicine, Institute of Metabolic Science, Cambridge Biomedical Campus, Cambridge, UK. ${ }^{3}$ Institute for Resilient Regions, University of Southern Queensland, Springfield, QLD, Australia. ${ }^{4}$ Pennington Biomedical Research Center, Baton Rouge, LA, USA. ${ }^{5}$ Department of Public and Occupational Health, Amsterdam Public Health research institute, VU University Medical Center, Amsterdam, Netherlands. ${ }^{6}$ Department of Sport Science, Norwegian School of Sport Sciences, Oslo, Norway. ${ }^{7}$ National Centre for Sport and Exercise Medicine, School of Sport, Exercise and Health SciencesLoughborough University, Loughborough, UK. ${ }^{8}$ Epidemiology, Biostatistics and Prevention Institute, University of Zurich, Zurich, Switzerland. ' Service of Endocrinology, Diabetes and Metabolism \& Service of Pediatric Endocrinology, Diabetology and Obesity, Lausanne University Hospital, Lausanne, Switzerland.
}

Received: 11 July 2017 Accepted: 7 December 2017

Published online: 20 December 2017

\section{References}

1. Gallacher JEJ. The case for large scale fungible cohorts. Eur J Pub Health. 2007:17:548-9.

2. Burton PR, Hansell AL, Fortier I, Manolio TA, Khoury MJ, Little J, et al. Size matters: just how BIG is BIG?: quantifying realistic sample size requirements for human genome epidemiology. Int J Epidemiol. 2009;38:263-73.

3. Thompson A. Thinking big: large-scale collaborative research in observational epidemiology. Eur J Epidemiol. 2009;24:727-31.

4. Wong M, Day N, Luan J, Chan K, Wareham N. The detection of geneenvironment interaction for continuous traits: should we deal with measurement error by bigger studies or better measurement? Int J Epidemiol. 2003;32:51-7.

5. Poitras VJ, Gray CE, Borghese MM, Carson V, Chaput J-P, Janssen I, et al. Systematic review of the relationships between objectively measured physical activity and health indicators in school-aged children and youth. Appl Physiol Nutr Metab. 2016;41:S197-239.

6. Ekelund U, Luan J, Sherar LB, Esliger DW, Griew P, Cooper A. Moderate to vigorous physical activity and sedentary time and cardiometabolic risk factors in children and adolescents. JAMA. 2012;307:704-12.

7. Bauman AE, Reis RS, Sallis JF, Wells JC, Loos RJF, Martin BW. Correlates of physical activity: why are some people physically active and others not? Lancet. 2012;380:258-71.

8. Atkin AJ, van Sluijs EMF, Dollman J, Taylor WC, Stanley RM. Identifying correlates and determinants of physical activity in youth: how can we advance the field? Prev Med. 2016;87:167-9.

9. Collins R. What makes UK Biobank special? Lancet. 2012:1173-4.

10. Peakman TC, Elliott P. The UK biobank sample handling and storage validation studies. Int J Epidemiol. 2008;37:i2-6.

11. Chen Z, Lee L, Chen J, Collins R, Wu F, Guo Y, et al. Cohort profile: the Kadoorie study of chronic disease in China (KSCDC). Int J Epidemiol. 2005;34:1243-9.

12. Chen Z, Chen J, Collins R, Guo Y, Peto R, Wu F, et al. China Kadoorie biobank of 0.5 million people: survey methods, baseline characteristics and long-term follow-up. Int J Epidemiol. 2011;40:1652-66.

13. Pearson H, Massive UK. Baby study cancelled. Nature. 2015:526:620-1.

14. McCarthy MUS. Cancels plan to study 100000 children from "womb" to age 21. BMJ. 2014:349

15. Riddoch C, Edwards D, Page A, Froberg K, Anderssen SA, Wedderkopp N, et al. The European youth heart study-cardiovascular disease risk factors in children: rationale, aims, study design, and validation of methods. J Phys Act Health. 2005;2:115-29.

16. Katzmarzyk PT, Barreira TV, Broyles ST, Champagne CM, Chaput J-P, Fogelholm M, et al. The international study of childhood obesity, lifestyle and the environment (ISCOLE): design and methods. BMC Public Health. 2013;13:900

17. van Stralen MM, te Velde SJ, Singh AS, De Bourdeaudhuij I, Martens MK, van der Sluis $M$, et al. EuropeaN Energy balance research to prevent excessive weight gain among youth (ENERGY) project: design and methodology of the ENERGY cross-sectional survey. BMC Public Health. 2011;11:65.

18. Riley RD, Lambert PC, Abo-Zaid G. Meta-analysis of individual participant data: rationale, conduct, and reporting. BMJ. 2010;340:C221.

19. Fortier I, Raina P, Van den Heuvel ER, Griffith LE, Craig C, Saliba M, et al. Maelstrom research guidelines for rigorous retrospective data harmonization. Int J Epidemiol. 2017:46:103-5.

20. Ridgway CL, Brage S, Sharp SJ, Corder K, Westgate KL, van Sluijs EM, et al. Does birth weight influence physical activity in youth? A combined analysis of four studies using objectively measured physical activity. PLoS One. 2011;6:e16125

21. Lakerveld J, Loyen A, Ling FCM, De Craemer $M$, van der Ploeg HP, O'Gorman DJ, et al. Identifying and sharing data for secondary data analysis of physical activity, sedentary behaviour and their determinants across the life course in Europe: general principles and an example from DEDIPAC. BMJ Open. 2017;7:e017489

22. Gaye A, Marcon Y, Isaeva J, LaFlamme P, Turner A, Jones EM, et al. DataSHIELD: taking the analysis to the data, not the data to the analysis. Int J Epidemiol. 2014:43:1929-44.

23. Doiron D, Burton P, Marcon Y, Gaye A, Wolffenbuttel BHR, Perola M, et al. Data harmonization and federated analysis of population-based studies: the BioSHaRE project. Emerg Themes Epidemiol. 2013;10:12. 
24. Fortier I, Burton PR, Robson PJ, Ferretti V, Little J, L'Heureux F, et al. Quality, quantity and harmony: the DataSHaPER approach to integrating data across bioclinical studies. Int J Epidemiol. 2010;39:1383-93.

25. Wolfson M, Wallace SE, Masca N, Rowe G, Sheehan NA, Ferretti V, et al. DataSHIELD: resolving a conflict in contemporary bioscience-performing a pooled analysis of individual-level data without sharing the data. Int J Epidemiol. 2010;39:1372-82.

26. Budin-Ljøsne I, Burton P, Isaeva J, Gaye A, Turner A, Murtagh MJ, et al. DataSHIELD: An Ethically Robust Solution to Multiple-Site Individual-Level Data Analysis. Public Health Genomics. S. Karger AG; 2014; 18: 87-96.

27. Doiron D, Raina P, Ferretti V, L'Heureux F. Fortier I. Facilitating collaborative research: Implementing a platform supporting data harmonization and pooling. 2012;21:221-4.

28. Jones EM, Sheehan NA, Masca N, Wallace SE, Murtagh MJ, Burton PR. DataSHIELD - shared individual-level analysis without sharing the data: a biostatistical. Perspective. 2012;21:231-9.

29. Griffith $L E$, van den Heuvel E, Fortier I, Sohel N, Hofer SM, Payette H, et al. Statistical approaches to harmonize data on cognitive measures in systematic reviews are rarely reported. J Clin Epidemiol. 2015;68:154-62.

30. Fortier I, Doiron D, Burton P, Raina P. Invited commentary: consolidating data harmonization-how to obtain quality and applicability? Am. J. Epidemiol. 2011;174:261-4-6.

31. Sherar LB, Griew P, Esliger DW, Cooper AR, Ekelund U, Judge $K$, et al. International children's accelerometry database (ICAD): design and methods. BMC Public Health. 2011;11:485.

32. Stierlin AS, De Lepeleere S, Cardon G, Dargent-Molina P, Hoffmann B, Murphy $\mathrm{MH}$, et al. A systematic review of determinants of sedentary behaviour in youth: a DEDIPAC-study. Int J Behav Nutr Phys Act. 2015;12:133.

33. Uijtdewilligen L, Nauta J, Singh AS, van Mechelen W, Twisk JWR, van der Horst $\mathrm{K}$, et al. Determinants of physical activity and sedentary behaviour in young people: a review and quality synthesis of prospective studies. $\mathrm{Br}$ J Sports Med. 2011;45:896-905.

34. Sterdt E, Liersch $\mathrm{S}$, Walter U. Correlates of physical activity of children and adolescents: a systematic review of reviews. Health Educ J. 2013;73:72-89.

35. Medical Research Council. MRC policy and guidance on sharing of research data from population and patient. Studies. 2017; Available from: https:// www.mrc.ac.uk/publications/browse/mrc-policy-and-guidance-on-sharingof-research-data-from-population-and-patient-studies/.

36. van Sluijs EMF, Fearne VA, Mattocks C, Riddoch C, Griffin SJ, Ness A. The contribution of active travel to children's physical activity levels: crosssectional results from the ALSPAC study. Prev Med. 2009:48:519-24.

37. Zahner L, Puder JJ, Roth R, Schmid M, Guldimann R, Pühse U, et al. A schoolbased physical activity program to improve health and fitness in children aged 6-13 years ("kinder-Sportstudie KISS"): study design of a randomized controlled trial [ISRCTN15360785]. BMC Public Health. 2006;6:147.

38. Niederer I, Kriemler S, Zahner L, Bürgi F, Ebenegger V, Hartmann T, et al. Influence of a lifestyle intervention in preschool children on physiological and psychological parameters (Ballabeina): study design of a cluster randomized controlled trial. BMC Public Health. 2009;9:94.

39. van Sluiis EMF, Skidmore PML, Mwanza K, Jones AP, Callaghan AM, Ekelund $\mathrm{U}$, et al. Physical activity and dietary behaviour in a population-based sample of British 10-year old children: the SPEEDY study (sport, physical activity and eating behaviour: environmental determinants in young people). BMC Public Health. 2008;8:388.

\section{Submit your next manuscript to BioMed Central and we will help you at every step:}

- We accept pre-submission inquiries

- Our selector tool helps you to find the most relevant journal

- We provide round the clock customer support

- Convenient online submission

- Thorough peer review

- Inclusion in PubMed and all major indexing services

- Maximum visibility for your research

Submit your manuscript at www.biomedcentral.com/submit

) Biomed Central 